Research Article

\title{
Prediction of Income of Rural Residents Based on Markov Model under the Background of Rural Revitalization
}

\author{
Xiaorong Li and Qianli Xing \\ Yancheng Institute of Technology, Yancheng 224051, Jiangsu Province, China \\ Correspondence should be addressed to Qianli Xing; xql@ycit.edu.cn
}

Received 10 November 2021; Accepted 7 December 2021; Published 26 December 2021

Academic Editor: Miaochao Chen

Copyright ( $\odot 2021$ Xiaorong Li and Qianli Xing. This is an open access article distributed under the Creative Commons Attribution License, which permits unrestricted use, distribution, and reproduction in any medium, provided the original work is properly cited.

\begin{abstract}
The income of rural residents is not only an important indicator to measure the development of rural economy, but also a key factor in the livelihood of farmers. The accurate prediction of income of rural residents can provide data supporting for promoting rural revitalization strategy. This paper selects per capita disposable income of rural residents in China as the research object and uses the macrostatistical data from 2011 to 2020 to predict farmers' income. Firstly, the grey prediction model is constructed, and the grey prediction value is corrected by Markov chain. The simulation value is compared with the real value. And the results show that the prediction accuracy of the model is higher. It shows that the results of using the grey Markov model to predict the income of rural residents in China from 2021 to 2025 are reliable. Finally, the article puts forward policy recommendations to promote the income of rural residents.
\end{abstract}

\section{Introduction}

The income of rural residents is not only an important indicator to measure the development of rural economy, but also a key factor in the livelihood of farmers. However, the production factors are still too concentrated in urban areas at present, which makes the rural economy develop slowly and restricts the growth of income of rural residents [1]. Therefore, China proposes to fully implement the strategy of rural revitalization and is committed to solving various problems in the process of rural development, so as to promote the synchronous development of rural and urban areas and accelerate the pace of urban-rural integration $[2,3]$. We are committed to achieving the goal of rural revitalization throughout China by 2050 and building a beautiful new countryside with prosperous industry, ecological livability, and rich farmers $[4,5]$.

With the implementation of the rural revitalization strategy, the mode of production and living conditions of farmers have improved significantly, and the per capita net income has also increased significantly [6]. But there is still a big gap from the full realization of the goal of rural revitalization [7]. Agricultural industry is the foundation of rural revitalization and the first priority of rural development. Industrial prosperity is the focus of rural revitalization and the basis for increasing farmers' income, agricultural development, and rural prosperity. It is very important for the development of China to solve the problem of farmers' income. At present, farmers' income mainly comes from agricultural production and wage income. Therefore, the focus of future work in rural areas of China is to realize industrial prosperity according to the strategy of rural revitalization, so as to promote the continuous improvement income of rural residents [8]. The income of farmers is an important symbol of rural development level and farmers' living conditions. On the one hand, it is affected by national macroeconomic policies, agricultural market regulation, rural population, and other factors [9-12]. On the other hand, the data statistics are difficult and heavy. Therefore, it is conducive to providing suggestions for the government to formulate rural development policies and providing reference for other countries by analyzing the key influencing factors of farmers' income and choosing an appropriate prediction method to predict farmers' income. 
The innovation contribution of this paper is to use the GM-Markov combination model to predict the income of farmers. The model is more accurate than the single grey prediction model, and the results are closer to the actual income of farmers. We take China as the research object and select the macrodata of per capita disposable income of rural residents from 2011 to 2020 and the grey Markov combination model is used to measure the income of rural residents in China. Then the GM-Markov model is used to predict the per capita disposable income of rural residents from 2021 to 2025, and policy suggestions are put forward to achieve the goal of rapid increase of income of rural families.

This paper is divided into five parts. The first and second parts describe the relevant research and development background. The third part includes data and model models and expounds the data sources and GM-Markov prediction model. The fourth part compares the results of two prediction models and predicts the income of rural residents in China. Finally, policy recommendations to promote income of rural residents are proposed. This method can accurately predict the income of rural residents, which is conducive to promoting the implementation of the strategy of rural revitalization.

\section{Related Work}

At present, the research on farmers' income mainly includes influencing factors and trend prediction. Many scholars have found that there are many factors affecting the income growth of farmers. For example, Zhou et al. [13] innovatively combined the mediating effect and multiple linear regression analysis to consider the role of the Internet in promoting the growth of farmers' income. The results showed that the use of the Internet will directly affect the growth of farmers' income. It is the main source of income for farmers by agricultural production, and it will affect crops because of climate and environmental changes. Therefore, climatic conditions and environmental conditions will also affect farmers' income $[14,15]$. We et al. [16] found that natural disasters are a key factor affecting household income and assets, so it is necessary to strengthen skills training for farmers to combat the effects of climate change and natural disasters by investing more working time and changing production methods. By studying the relationship between land transfer incentive policies and farmers' income, Peng et al. [17] found that improving land property rights system is conducive to promoting the transfer of rural land resources, which can improve farmers' income. In addition, some scholars have found that rural credit is conducive to increasing farmers' income and improving rural economic level. Liu et al. [18] found that the education level and health level of farmers will affect the availability of rural credit. In addition, social capital also has an impact on whether farmers can obtain loans, such as interpersonal capital and political relationship capital. In the prediction of the income of farmers, Zhang et al. [19] constructed a fuzzy grey prediction model to predict the per capita income of rural residents and tested the error of the model according to the fuzzy possibility.
In recent years, many scholars have used different methods to predict the trend of income change, including financial income, tax budget income, and corporate income. Zhang et al. [20] used time series method to forecast financial revenue in China. In addition, they considered the influencing factor of inflation in the prediction and then used the consumer price index to eliminate the impact of inflation. Koniagina [21] used digital tools to predict tax revenue and found problems with these tools. Then he put forward suggestions for improvement according to these problems, which laid the foundation for the tax authorities to develop measures. Zheng et al. [22] used neural network method to predict hotel revenue and improved the prediction accuracy, so as to improve the hotel revenue management system. Fang [23] used grey prediction method to predict the per capita income level of a region according to the per capita income and its capacity. The results showed that the plan of doubling per capita income in the region can be achieved. However, by studying the case of per capita disposable income in Hebei Province, Wang found that the sample length will affect the use of grey prediction model, which is not suitable for predicting the case of too long sample length [24]. Therefore, we should pay attention to the sample length when using the grey prediction model.

\section{Data and Model Description}

3.1. Data Sources and Description. It can be seen from Figure 1 that the average per capita disposable income of Chinese peasant households showed an overall upward trend from 2011 to 2019, but the nominal growth rate and actual growth rate of per capita disposable income showed a downward trend. During this period, the overall growth rate of the income of rural residents is in the "ladder" decline stage, and the nominal growth rate has been higher than the actual growth rate. Under the new normal background of China's economic growth rate from high-speed growth to medium-high growth, farmers' own resources are limited and the efficiency of factor allocation is not good. Therefore, the income growth rate of rural residents in China is weak, resulting in a slowdown in growth. Although the growth rate of income has slowed down, the overall remains on the rise with the implementation of rural revitalization policy in the future.

3.2. Model Selection and Description. The prediction of income includes many kinds of research methods, but in the actual prediction, the selection of only one prediction method may lead to low prediction accuracy. Therefore, two or more prediction methods can be combined to give full play to their respective advantages and achieve mutual benefit. GM $(1,1)$ prediction method has the advantages of simple algorithm, convenient operation and inspection, and low data requirements. It can predict the future development trend without too much historical data. In the case of less historical data, the prediction results can achieve good accuracy for a class of data that is increasing or decreasing. However, GM $(1,1)$ model is only applicable to sequences 


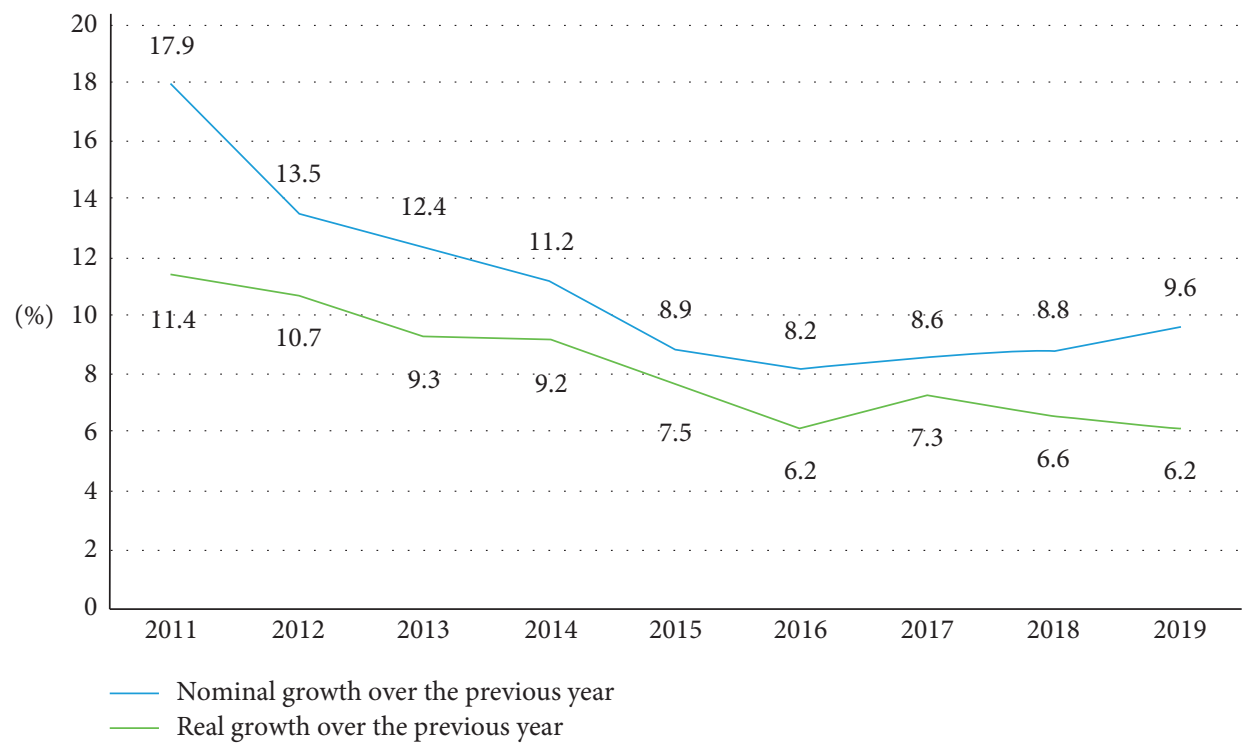

FIGURE 1: Growth rate of per capita disposable income in rural area of China.

with strong exponential law. It can only describe the process of change and is not suitable for data sequences with large fluctuations. Markov model requires a large number of samples, and samples need to have stable characteristics, so as to make a more accurate medium- and long-term prediction of volatility sample.

The income of rural residents is a dynamic and changing system. There is a certain random volatility. And its development presents a trend of nonstationary random process. GM-Markov prediction model combines the advantages of grey model and Markov model and makes up for their shortcomings. Therefore, GM-Markov model can make a more accurate prediction of income of rural residents. The basic method of building GM-Markov model is as follows: firstly, the predicted value and relative error of grey
GM $(1,1)$ are obtained by grey theory; then the relative error interval is divided into 3-5 states; finally, Markov theory is used to construct the probability transfer matrix of GM $(1,1)$ model in known years, and the results of GM $(1,1)$ model are modified.

3.2.1. Grey Prediction Model. Grey model is a differential equation established by using the original data sequence as the generating principle $[25,26]$.

(1) Let the original time series be $X^{(0)}=\left(X^{(0)}(1)\right.$, $\left.X^{(0)}(2), \cdots, X^{(0)}(n)\right)$.

(2) Accumulate the original time series to generate a new sequence.

$$
X^{(1)}=\left(X^{(1)}(1), X^{(1)}(2), \cdots, X^{(0)(1)}(n)\right)=\left(X^{(1)}(1),\left(X^{(1)}(1)+X^{(0)}(2), \cdots, X^{(1)}(n-1)+\cdots X^{(0)}(n)\right)\right.
$$

where $X^{(1)}(k)=\sum_{i=1}^{k} X^{(0)}(i)(k=1,2, \cdots, n)$.

(3) Get the sequence of mean values. The mean value sequence of the sequence obtained after accumulation is obtained, namely, $Z^{(1)}=\left(Z^{(1)}(2), Z^{(1)}(3)\right.$, $\left.\cdots, Z^{(1)}(n)\right)$.

$$
Z^{(1)}(k)=0.5 X^{(1)}(k)+0.5 X^{(1)}(k-1) .
$$

(4) Establish grey differential equation.

$$
X^{(0)}(k)+a Z^{(1)}(k)=b(k=2,3, \cdots, n) .
$$

The corresponding whitening differential equation is

$$
\frac{d X^{(1)}}{d t}+a X^{(1)}(t)=b \text {. }
$$

In the formula, $X^{(0)}(k)$ is called grey derivative, $a$ is called development coefficient, $Z^{(1)}(k)$ is called whitening background value, and $b$ is called grey action.

(5) Parameter estimation using least square method: substituting time $k=2,3, \cdots, n$ into the formula yields 


$$
\begin{aligned}
& \left\{\begin{array}{c}
X^{(0)}(2)+a Z^{(1)}(2)=b \\
X^{(0)}(3)+a Z^{(1)}(3)=b \\
\vdots \quad \vdots \quad \vdots \\
X^{(0)}(n)+a Z^{(1)}(n)=b
\end{array}\right. \\
& Y_{N}=\left(X^{(0)}(2), X^{(0)}(3), \cdots, X^{(0)}(n)\right)^{T} \text {, } \\
& u=(a, b)^{T} \text {, } \\
& B=\left[\begin{array}{cc}
-Z^{(1)}(2) & 1 \\
-Z^{(1)}(3) & 1 \\
\vdots & \vdots \\
-Z^{(1)}(n) & 1
\end{array}\right] .
\end{aligned}
$$

$\mathrm{YN}$ is called the data vector, $\mathrm{B}$ is the data matrix, $u$ is the parameter vector, and then $\operatorname{GM}(1,1)$ can be expressed as a matrix equation, namely $Y_{N}=B \cdot u$.

Method for determining parameter vector $\mathrm{u}$ : if there exists $\left(B^{T} \cdot B\right)^{-1}$, there is $u=(a, b)^{T}=$ $\left(B^{T} B\right)^{-1} B^{T} Y_{N}$.

$$
\begin{aligned}
& a=\frac{C D-(n-1) E}{(n-1) F-C^{2}}, \\
& \hat{b}=\frac{D F-C E}{(n-1) F-C^{2}}, \\
& C=\sum_{k=2}^{n} Z^{(1)}(k), \\
& D=\sum_{k=2}^{n} Z^{(0)}(k), \\
& E=\sum_{k=2}^{n} Z^{(1)}(k) X^{(0)}(k), \\
& F=\sum_{k=2}^{n}\left(Z^{(1)}(k)\right)^{2} .
\end{aligned}
$$

So we can calculate the predicted value by solving the equation.

$X^{(1)}(k+1)=\left(X^{(0)}(1)-\frac{b}{a}\right) e^{-a k}+\frac{b}{a}(k=1,2, \cdots, n-1)$.

However, there may be many research problems that are not suitable for GM $(1,1)$ prediction model, so it is necessary to carry out residual test and posterior difference test.

(6) Residual test: residual test is to test the residuals of predicted and actual values. First calculate $X^{(1)}(i+1)$, and $X^{(1)}(i+1)$ cumulative reduction is generated $X^{(0)}(i)$. And then calculate the absolute residual sequence and relative residual sequence.

$$
\begin{aligned}
\Delta^{(0)} & =\left(\Delta^{(0)}(i), i=1,2, \cdots n\right), \\
\Delta^{(0)}(i) & =X^{(0)}(i)-\hat{X}^{(0)}(i), \\
\phi & =\left(\phi_{i}, i=1,2, \cdots, n\right), \\
\phi_{i} & =\left(\frac{\Delta^{(0)}(i)}{X^{(0)}(i)}\right) \% .
\end{aligned}
$$

(7) Posterior difference test: the posteriori difference test is to test the statistical characteristics of the residual distribution.

Calculate the average value of the original sequence:

$$
\bar{X}^{(0)}=\frac{1}{n} \sum_{i=1}^{n} X^{(0)}(i) \text {. }
$$

Calculate the mean square error of the original sequence:

$$
S_{1}=\left\{\frac{\sum_{i=1}^{n}\left[X^{(0)}(i)-\bar{X}^{(0)}\right]^{2}}{n-1}\right\}^{1 / 2} .
$$

The mean of residual is given by

$$
\bar{\Delta}^{(0)}=\frac{1}{n} \sum_{i=1}^{n} \bar{\Delta}^{(0)}(i)
$$

The mean square error of residuals is

$$
S_{2}=\left\{\frac{\sum_{i=1}^{n}\left[\Delta^{(0)}(i)-\bar{\Delta}^{(0)}\right]^{2}}{n-1}\right\}^{1 / 2} .
$$

Calculate mean variance ratio $\mathrm{C}$ :

$$
C=\frac{S_{2}}{S_{1}} \text {. }
$$

Calculate small residual probability:

$$
\begin{aligned}
P & =p\left\{\left|\Delta^{(0)}(i)-\bar{\Delta}^{(0)}\right|<0.6745 S_{1}\right\}, \\
S_{0} & =0.6745 S_{1}, \\
\lambda & =\left|\Delta^{(0)}(i)-\bar{\Delta}^{(0)}\right|, \\
P & =p\left\{\lambda<S_{0}\right\} .
\end{aligned}
$$

If for a given $C_{0}>0$, when $C<C_{0}$, the model is called mean square error ratio qualified model; if for a given $P_{0}>0$, when $P>P_{0}$, the model is called small residual probability qualified model.

If the residual value and the posteriori error test are within the allowable range, it can be considered that the 
model used is reasonable and can be used for prediction; otherwise, it cannot be used for prediction. In summary, the flowchart of constructing grey GM $(1,1)$ model is shown in Figure 2.

3.2.2. Markov Prediction Model. Markov prediction model is based on the current state of things and the trend of state transition. It predicts that things may be in a state in the future interval and obtains more accurate prediction value by taking the midpoint of the interval. Markov chain describes a sequence of states, each of which depends on the previous finite states. It is a random process of transition from one state to another in state space. At present, Markov chain is widely used in speech recognition, text identification, path identification, and many other fields of artificial intelligence as a simple concept to explain complex time process. Markov prediction model is expressed as $x(k)=P(1)^{k}$, where $x(k)$ is the state of the predicted sample at time $k$ and $P(1)$ is the one-step transition probability matrix [27].

\subsubsection{GM-Markov Prediction Model}

(1) Grey GM $(1,1)$ prediction model is constructed and grey prediction value is obtained [28].

(2) The relative variation between the original value and the simulated value is calculated.

$$
\begin{aligned}
& P_{w}=\frac{\Delta k}{x^{(0)}(k)} \times 100 \%, \\
& \Delta k=x^{(0)}(k)-\hat{x}^{(0)}(k) .
\end{aligned}
$$

(3) The Markov state is divided according to relative variation.

$$
E_{i}=\left[Q_{i 1}, Q_{i 2}\right](i=1,2, \cdots, k) .
$$

Among them, $Q_{i 1}$ is the minimum limit of relative variation of each interval and $Q_{\mathrm{i} 2}$ is the maximum limit of relative variation of each interval.

(4) Calculate the probability of state transition matrix:

$$
P_{i j}=\frac{n_{i j}(k)}{n_{i}} .
$$

In the formula, $n_{i j}(k)$ represents the number of times that state $A i$ passes through one step to state $A j$ and $n i$ represents the total number of times that $A i$ appears in the sample. The specific transfer matrix is as follows. This can determine the initial state of the matrix, so as to predict the development of things in the future.

$$
P_{k}=\left(\begin{array}{cccc}
p_{11}(k) & p_{12}(k) & \cdots & p_{1 n}(k) \\
p_{21}(k) & p_{22}(k) & \cdots & p_{2 n}(k) \\
\vdots & \vdots & \vdots & \vdots \\
p_{n 1}(k) & p_{n 2}(k) & \cdots & p_{n n}(k)
\end{array}\right) .
$$

(5) After determining the change interval of income in the future, it is necessary to take the midpoint of the interval to correct the grey prediction value, and finally get the grey Markov prediction value.

$$
Y_{G-M}=\frac{\hat{x}^{(0)}(k+1)}{1-1 / 2\left(Q_{i 1}+Q_{i 2}\right)} \text {. }
$$

In summary, the flowchart of constructing GM-Markov prediction model is shown in Figure 3.

\section{Example Analysis}

4.1. Gary GM $(1,1)$ Model. According to the data of per capita disposable income of rural residents in China from 2011 to 2020 and the principle of grey prediction model, Matlab program is used to predict per capita disposable income of rural residents in China over the years and in the next five years. Then two test methods are used to test the accuracy of the model to make the prediction results more convincing. The data come from "China Rural Statistical Yearbook". The results of the grey prediction model are as follows:

$$
X^{(1)}(k+1)=96775.21804 e^{0.086 k}-89381.31804(k=0,1,2, \cdots, 20) .
$$

Substituting the data of each year into the above equation, the calculation results are accumulated and reduced to obtain the simulation value, residual variation, and relative variation of the original sample, as shown in Table 1.

It can be seen from the above that the residuals are not too large and are within an acceptable range, so this model can be used for prediction. In order to improve reliability, the following posterior difference test is performed:

Calculate the average value of the original sequence:

$$
\bar{X}^{(0)}=\frac{1}{10} \sum_{i=1}^{10} X^{(0)}(i)=12068.79 .
$$

Calculate the mean square error of the original sequence:

$$
S_{1}=\left\{\frac{\sum_{i=1}^{10}\left[X^{(0)}(i)-\bar{X}^{(0)}\right]^{2}}{9}\right\}^{1 / 2}=3248.19 .
$$




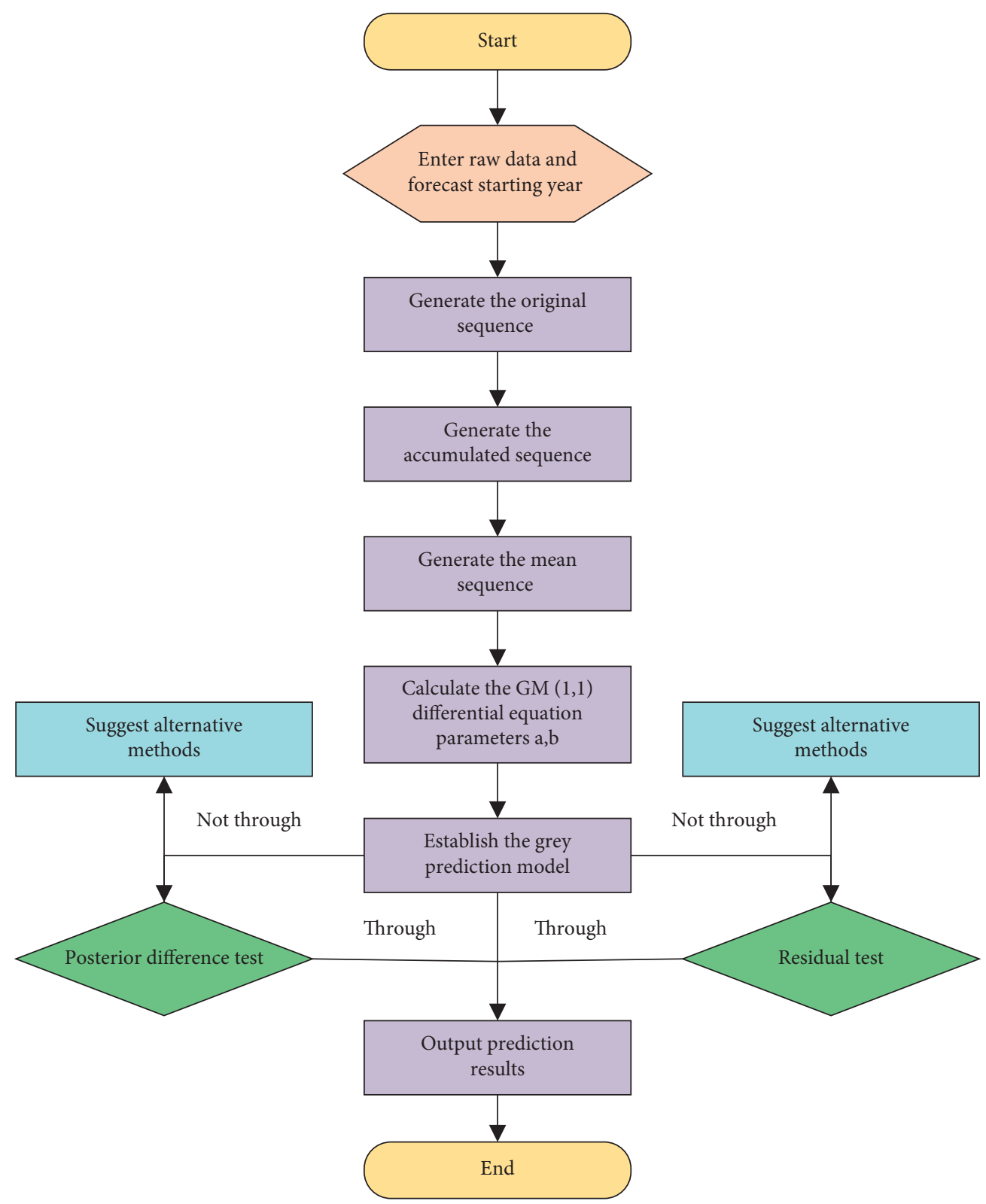

Figure 2: Modeling flowchart of the grey prediction model.

The mean of residual is given by

$$
\bar{\Delta}^{(0)}=\frac{1}{10} \sum_{i=1}^{10} \bar{\Delta}^{(0)}(i)=2.46 .
$$

The mean square error of residuals is given by

$$
S_{2}=\left\{\frac{\sum_{i=1}^{10}\left[\Delta^{(0)}(i)-\bar{\Delta}^{(0)}\right]^{2}}{9}\right\}^{1 / 2}=153.40 .
$$

Calculate mean variance ratio C:

$$
C=\frac{S_{2}}{S_{1}}=0.047
$$

Calculate small residual probability:

$$
\begin{aligned}
S_{0} & =0.6745 S_{1}=2190.90, \\
\lambda & =\left|\Delta^{(0)}(i)-\bar{\Delta}^{(0)}\right|=\left(\begin{array}{c}
2.46,315.08,57.24,149.23,152.53, \\
81.14,45.95,27.08,119.09,200.24
\end{array}\right) .
\end{aligned}
$$

From the above data, $P=p\left\{\lambda<S_{0}\right\}=1$. As can be seen from Table 2, given $P_{0}=0.95, C_{0}=0.35, P>P_{0}$, and $C<C_{0}$, so the grey prediction model can be rated as excellent. Therefore, this model can be used to predict the per capita disposable income of rural households in China from 2021 to 2025, as shown in Figure 4. 


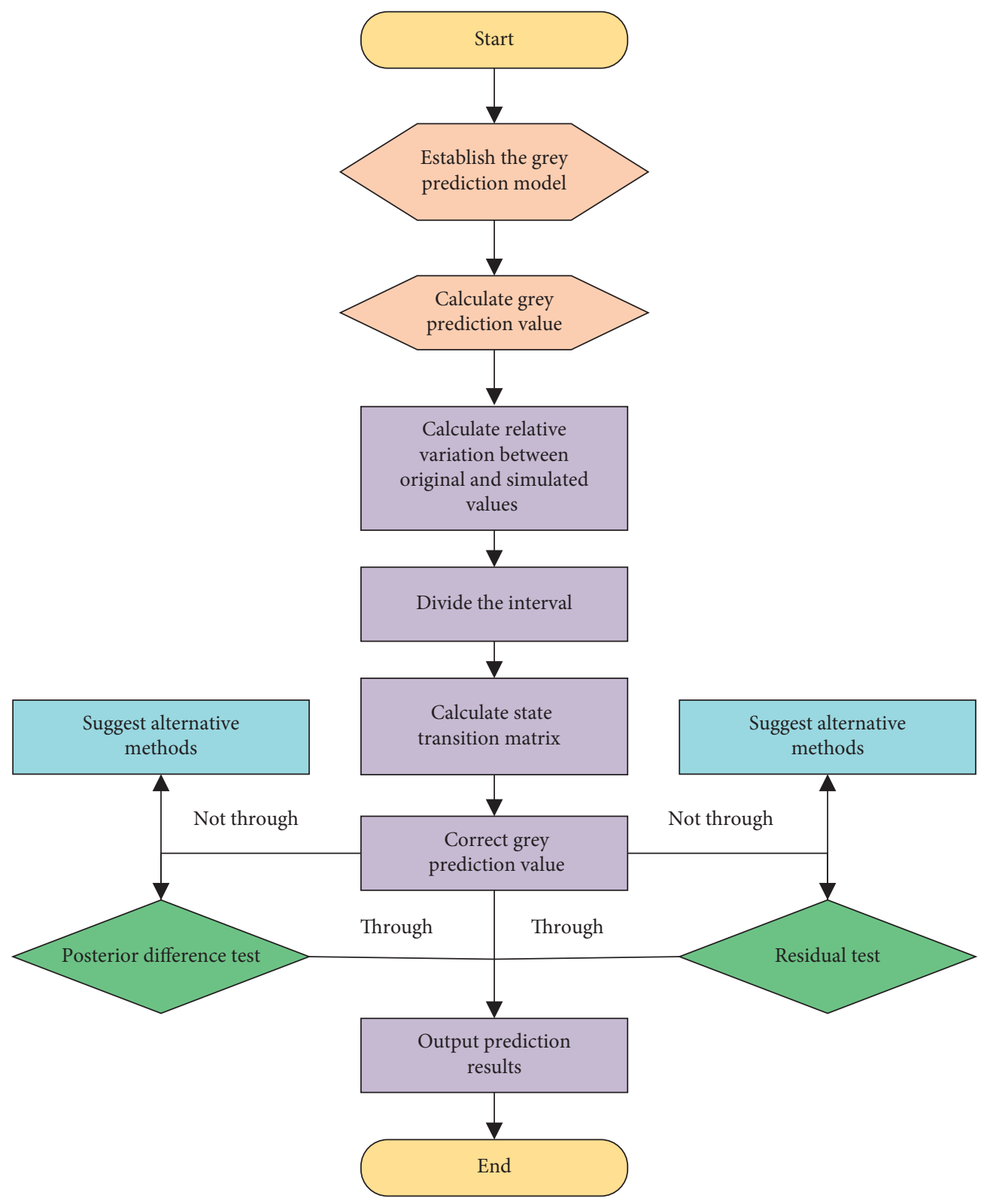

Figure 3: Modeling flowchart of the GM-Markov prediction model.

TABLE 1: Grey system prediction and verification of per capita disposable income of rural residents in China from 2011 to 2020.

\begin{tabular}{ccccc}
\hline Year & $\begin{array}{c}\text { Original } \\
\text { value }\end{array}$ & $\begin{array}{c}\text { Predictive } \\
\text { value }\end{array}$ & Residual & $\begin{array}{c}\text { Relative } \\
\text { variation }\end{array}$ \\
\hline 2011 & 7393.9 & 7393.9 & 0.000 & $0.00 \%$ \\
2012 & 8389.3 & 8701.9 & -312.613 & $-3.73 \%$ \\
2013 & 9429.6 & 9484.4 & -54.779 & $-0.58 \%$ \\
2014 & 10488.9 & 10337.2 & 151.697 & $1.45 \%$ \\
2015 & 11421.7 & 11266.7 & 154.988 & $1.36 \%$ \\
2016 & 12363.4 & 12279.8 & 83.599 & $0.68 \%$ \\
2017 & 13432.4 & 13384.0 & 48.414 & $0.36 \%$ \\
2018 & 14617.0 & 14587.5 & 29.542 & $0.20 \%$ \\
2019 & 16020.7 & 15899.1 & 121.555 & $0.76 \%$ \\
2020 & 17131.0 & 17328.8 & -197.778 & $-1.15 \%$ \\
\hline
\end{tabular}

TABLE 2: Reference table for posterior difference test.

\begin{tabular}{lcccc}
\hline Accuracy grade & I & II & III & IV \\
\hline$P$ & $>0.95$ & $>0.8$ & $>0.7$ & $\leq 0.7$ \\
$C$ & $<0.35$ & $<0.5$ & $<0.65$ & $\geq 0.65$ \\
\hline
\end{tabular}

4.2. Markov Chain Modified Grey Prediction Value. In order to make the predicted value of income of rural residents in China closer to the real value, the grey prediction value is modified by Markov chain. In this paper, according to the relative variation in Table 1, it is divided into four intervals. The minimum interval is limited to $-4 \%$ and the maximum interval is limited to $2 \%$. Besides, the interval division is not included, as shown in Table 3. 


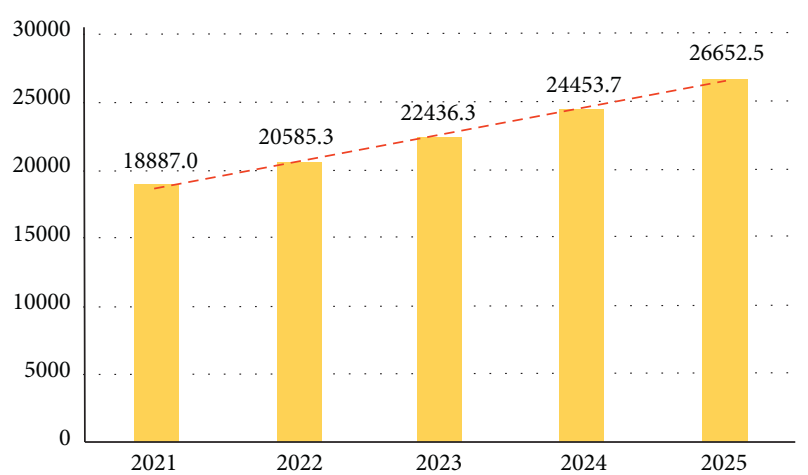

FIgURE 4: The grey system prediction results of per capita disposable income of rural residents in China from 2021 to 2025.

TABLE 3: Division of income state of Chinese farmers.

\begin{tabular}{lccc}
\hline Label & Interval & Year & Number \\
\hline A1 & $(-4 \%,-2 \%)$ & 2012 & 1 \\
A2 & $(-2 \%, 0 \%)$ & $2011,2013,2020$ & 3 \\
A3 & $(0 \%, 1 \%)$ & $2016--2019$ & 4 \\
A4 & $(1 \%, 2 \%)$ & 2014,2015 & 2 \\
\hline
\end{tabular}

The resulting one-step state transition probability matrix is as follows:

$$
P(1)=\left(\begin{array}{llll}
0 & 1 & 0 & 0 \\
\frac{2}{3} & 0 & 0 & \frac{1}{3} \\
0 & \frac{1}{4} & \frac{3}{4} & 0 \\
0 & 0 & \frac{1}{2} & \frac{1}{2}
\end{array}\right) .
$$

The grey Markov prediction value from 2011 to 2020 is calculated and compared with GM $(1,1)$ prediction value, as shown in Table 4. As can be seen from the table, the predicted value modified by Markov is closer to the real value.

The grey Markov model is established by using Markov theory. The state transition probability matrix is established by dividing the relative error states, and the prediction error of the grey GM $(1,1)$ model is corrected. As shown in Figure 5, the fluctuation of relative error of grey Markov prediction value is smaller compared with GM $(1,1)$, and the prediction accuracy of the model is obviously improved. It shows that the grey Markov chain model is more reliable than the single GM $(1,1)$ grey model, and the prediction results are closer to the actual income of farmers. The results of the grey prediction model and grey Markov prediction model are shown in Figure 6.

4.3. Posterior Difference Test. The grey Markov prediction value is close to the real value, but it needs to be tested by the posterior difference ratio $\mathrm{C}$ and the probability of small error $\mathrm{P}$, so as to ensure the reliability of the model.
The mean of residual is given by

$$
\bar{\Delta}^{(0)}=\frac{1}{10} \sum_{i=1}^{10} \bar{\Delta}^{(0)}(i)=-1.77 .
$$

The mean square error of residuals is given by

$$
S_{2}=\left\{\frac{\sum_{i=1}^{10}\left[\Delta^{(0)}(i)-\bar{\Delta}^{(0)}\right]^{2}}{9}\right\}^{1 / 2}=167.31 \text {. }
$$

Calculate mean variance ratio $\mathrm{C}$ :

$$
C=\frac{S_{2}}{S_{1}}=0.052 \text {. }
$$

Calculate small residual probability:

$$
\begin{aligned}
& S_{0}=0.6745 S_{1}=2190.90, \\
& \lambda=\left|\Delta^{(0)}(i)-\bar{\Delta}^{(0)}\right|=\left(\begin{array}{c}
1.77,255.22,95.67,302.85,169.81, \\
185.24,65.49,71.54,78.13,85.31
\end{array}\right) .
\end{aligned}
$$

From the above data, $P=p\left\{\lambda<S_{0}\right\}=1$. As can be seen from Table 1, given $P_{0}=0.95, C_{0}=0.35, P>P_{0}$, and $C<C_{0}$, so the GM-Markov prediction model can be rated as excellent. Therefore, the GM-Markov prediction model has passed the posterior difference test, and the prediction of income of Chinese farmers is reliable. The results of using the grey Markov prediction model to predict the income of farmers in China from 2021 to 2025 are shown in Table 5.

\section{Conclusions and suggestions}

5.1. Conclusions. It is helpful to dynamically grasp the changing trend of income of rural residents by strengthening the prediction of income, so as to formulate scientific measures to increase income. Taking China as a sample, this paper uses statistical data to establish a grey Markov prediction model. The fitting degree of prediction results and measured values of the GM-Markov prediction model is higher than that of GM $(1,1)$ prediction model. It can objectively reflect the trend of per capita disposable income of rural residents in China, and the predicted results are more accurate.

The prediction results show that the per capita disposable income of rural residents in China will exceed CNY 20,000 in quantity and reach CNY 20381.4 by 2022. Besides, it will reach CNY 25876.3 by 2025 and twice that of 2016. The rural economy is the starting point that affects the implementation and implementation of the rural revitalization strategy, and it is the key to achieve the expropriation growth of farmers and industrial prosperity and development. We should rely on a good macroenvironment to promote economic and social development with a longer period of time, a higher level, and better quality at a new starting point, so as to achieve the goal of rural revitalization. 
TABLE 4: Comparison of GM $(1,1)$ and GM-Markov prediction results.

\begin{tabular}{|c|c|c|c|c|c|}
\hline \multirow{2}{*}{ Year } & \multirow{2}{*}{ Original value } & \multicolumn{2}{|c|}{$\mathrm{GM}(1,1)$} & \multicolumn{2}{|c|}{ GM-Markov } \\
\hline & & Predictive value & Relative variation & Predictive value & Relative variation \\
\hline 2011 & 7393.9 & 7393.9 & $0.00 \%$ & 7393.9 & $0.00 \%$ \\
\hline 2012 & 8389.3 & 8701.9 & $-3.73 \%$ & 8448.5 & $-0.71 \%$ \\
\hline 2013 & 9429.6 & 9484.4 & $-0.58 \%$ & 9390.5 & $0.41 \%$ \\
\hline 2014 & 10488.9 & 10337.2 & $1.45 \%$ & 10036.1 & $4.32 \%$ \\
\hline 2015 & 11421.7 & 11266.7 & $1.36 \%$ & 11438.3 & $-0.15 \%$ \\
\hline 2016 & 12363.4 & 12279.8 & $0.68 \%$ & 12466.8 & $-0.84 \%$ \\
\hline 2017 & 13432.4 & 13384.0 & $0.36 \%$ & 13451.2 & $-0.14 \%$ \\
\hline 2018 & 14617.0 & 14587.5 & $0.20 \%$ & 14660.8 & $-0.30 \%$ \\
\hline 2019 & 16020.7 & 15899.1 & $0.76 \%$ & 15979.0 & $0.26 \%$ \\
\hline 2020 & 17131.0 & 17328.8 & $-1.15 \%$ & 17415.9 & $-1.66 \%$ \\
\hline
\end{tabular}

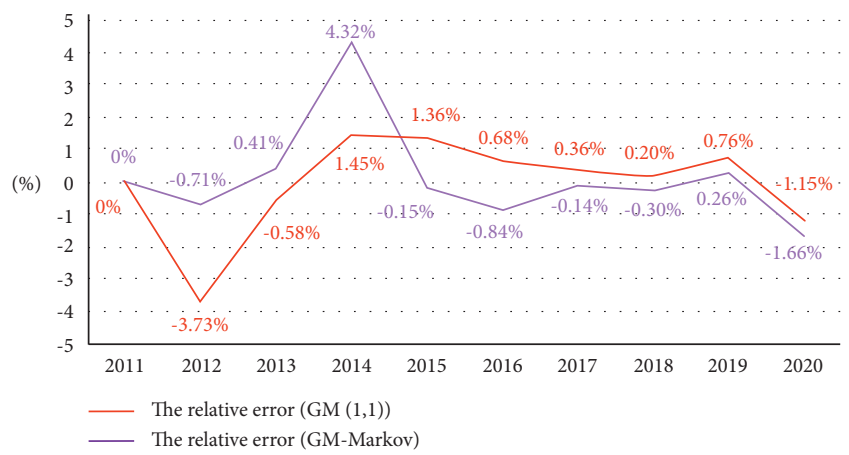

FIgURE 5: Relative error comparison between GM $(1,1)$ model and GM-Markov model.

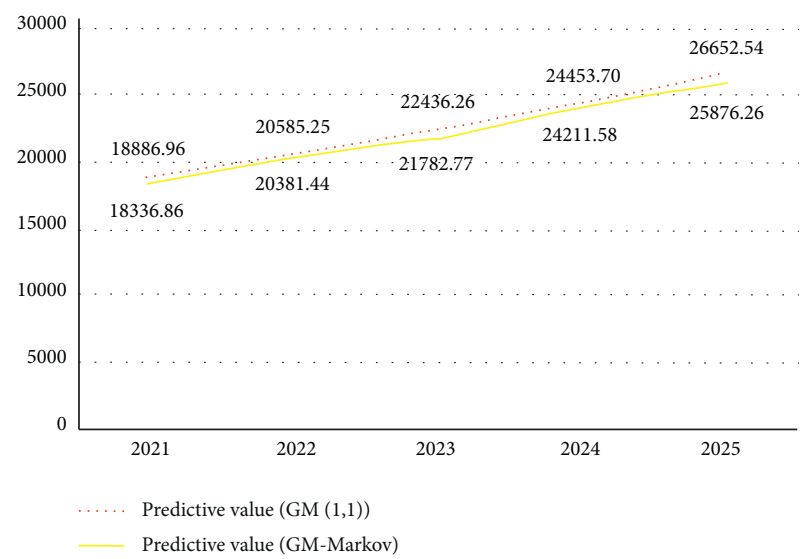

Figure 6: Predictive value comparison between GM $(1,1)$ model and GM-Markov model.

5.2. Suggestions. The government should increase the income of rural residents and narrow the urban-rural income gap by taking targeted measures and strengthening policy support. This is a big article in the process of rural revitalization and an inevitable choice to achieve the goal of common prosperity. Specifically, the government can formulate policies from the following five aspects.

5.2.1. Mining the Potential of Increasing Income and Enriching People in Agricultural and Rural Areas. The government should adhere to the market and consumption
TABLE 5: GM-Markov prediction of per capita disposable income of rural residents in China from 2021 to 2025.

\begin{tabular}{lccccc}
\hline Year & 2021 & 2022 & 2023 & 2024 & 2025 \\
\hline Predictive value & 18336.9 & 20381.4 & 21782.8 & 24211.6 & 25876.3 \\
\hline
\end{tabular}

orientation and achieve the goal of continuously improving quality, efficiency, and competitiveness by promoting the development of breeding industry in the direction of scale, standardization, branding, and greening. Specifically, it can be achieved through the implementation of the development of rural industries, the extension of the agricultural value chain, and the development of agricultural income insurance.

5.2.2. Promoting Higher Quality and Full Employment of Rural Labour. The government should take human urbanization as the fundamental goal and continue to promote the division of labor in rural areas. It is an important option to increase the income of farmers by promoting rural labor to more efficient areas and sectors of employment. Specifically, it can be achieved by guiding out of employment, expanding rural employment, and innovative employment areas and methods.

5.2.3. Optimizing the Institutional Environment for the Steady Increase of Property Income of Farmers. The government should establish a modern rural property rights system, promote the market-oriented allocation of factors, and improve the mechanism that factors are evaluated by the market and determined by contribution. Specifically, we can achieve the goal by improving the rural land management system, deepening the reform of the rural collective property rights system, and improving the rural property rights of farmers.

5.2.4. Improving the Security Mechanism of Transfer Income Focusing on Fair Distribution. It is an important manifestation of the effective role of the government by increasing the transfer income of farmers. There is much room for increasing direct support for income of farmers. We should improve the direct subsidy policy for farmers and strengthen 
the protection of farmers' life. We should address the problem of inadequate implementation of corrective policies and ensure that rural residents have the most basic necessities of life. In addition, it is necessary to improve the minimum living security system and assessment mechanisms, such as the basic pension insurance system and basic medical insurance system.

\subsubsection{Accelerating the Pace of Industrial Integration and} Agricultural Industrial Structure Upgrading. It is conducive to promoting the upgrading of agricultural industrial structure by industrial integration. If the rationalization level of agricultural industrial structure is improved, the proportion of production between the various production departments within the agriculture will become coordinated, and agricultural production and operation activities tend to maximize revenue, which can improve farmers' family operating income to a certain extent. Specifically, it can be achieved by focusing on cultivating rural rich industry, perfecting the innovation mechanism of agricultural technology, and formulating a reasonable profit distribution mechanism for industrial integration.

\section{Data Availability}

The data used to support the findings of this study are available from the corresponding author upon request.

\section{Conflicts of Interest}

The authors declare that they have no conflicts of interest.

\section{References}

[1] D. Jaitiang, W. C. Huang, and S. H. Yang, "Does income inequality exist among urban farmers? A demonstration of lorenz curves from northern Thailand," Sustainability, vol. 13, no. 9, pp. 1-16, 2021.

[2] L. Guo, "Path choice of urban-rural integration system in west China under the vision of rural revitalization," in Proceedings of the 8th International Conference on Management and Computer Science (ICMCS 2018), pp. 166-170, Shenyang, China, August 2018.

[3] H. A. Wei, C. Ywb, and E. Jcd, "Rural nonfarm sector and rural residents' income research in China. An empirical study on the township and village enterprises after ownership reform (2000-2013)," Journal of Rural Studies, vol. 82, pp. 161-175, 2021.

[4] M. Tan, Q. Liu, and N. Huang, "Path model and countermeasures of China's targeted poverty alleviation and rural revitalization," Revista de Cercetare şi Intervenţie Socială, vol. 70, pp. 312-332, 2020.

[5] X. Zeng, Y. Zhao, and Z. Cheng, "Development and research of rural renewable energy management and ecological management information system under the background of beautiful rural revitalization strategy," Sustainable Computing: Informatics and Systems, vol. 30, no. 11, p. 100553, 2021.

[6] X. Chun, "Agricultural and rural development under the revitalization of rural areas: a case study of meishan city," in Proceedings of the 5th International Conference on Business,
Economics and Management(BUSEM 2018), pp. 392-396, Yinchuan, China, July 2018.

[7] J. Han, "How to promote rural revitalization via introducing skilled labor, deepening land reform and facilitating investment?" China Agricultural Economic Review, vol. 12, no. 4, pp. 577-582, 2020.

[8] S. Lou, "An empirical study on the influencing factors of farmers' wage income in heilongjiang province," in Proceedings of the 7th International Conference on Education, Management, Information and Computer Science (ICEMC 2017), pp. 271-274, Shenyang, China, June 2017.

[9] A. St, B. Yza, and Y. A. Fang, "The impact of Nanshan National Park concession policy on Farmers' income in China," Global Ecology and Conservation, vol. 31, no. 5, Article ID e01804, 2021.

[10] Y. Z. Weng, Y. T. Zeng, and W. S. Lin, "Do rural highways narrow Chinese farmers' income gap among provinces?" Journal of Integrative Agriculture, vol. 20, no. 4, p. 10, 2021.

[11] X. Su, K. Lu, and X. Hu, "Reforms on county-level fiscal governance in China: impact on urban-rural income inequality," International Review of Psycho-Analysis, vol. 24, no. 2, pp. 15-34, 2019.

[12] B. Bihari, M. Singh, and R. Bishnoi, "Issues, challenges and strategies for doubling the farmers' income in India -A review," Indian Journal of Agricultural Sciences, vol. 89, no. 8, pp. 1219-1224, 2020.

[13] X. Zhou, Y. Cui, and S. Zhang, "Internet use and rural residents' income growth," China Agricultural Economic Review, vol. 12, no. 2, pp. 315-327, 2020.

[14] A. Hussain, J. A. Memon, and S. Hanif, "Weather shocks, coping strategies and farmers' income: a case of rural areas of district Multan, Punjab," Weather and Climate Extremes, vol. 30, Article ID 100288, 2020.

[15] B. Amfo and E. B. Ali, "Climate change coping and adaptation strategies: how do cocoa farmers in Ghana diversify farm income?" Forest Policy and Economics, vol. 119, Article ID 102265, 2020.

[16] B. Wei, G. Su, Y. Li, and Y. Ma, "Livelihood strategies of rural households in ning'er earthquake-stricken areas, yunnan Province, China," Sustainability, vol. 11, no. 21, p. 5905, 2019.

[17] K. Peng, C. Yang, and Y. Chen, "Land transfer in rural China: incentives, influencing factors and income effects," Applied Economics, no. 1, pp. 1-14, 2020.

[18] J. Liu, G. Zhang, and J. Zhang, "Human capital, social capital, and farmers' credit availability in China: based on the analysis of the ordered probit and PSM models[J]," Sustainability, vol. 12, no. 4, pp. 4-15, 2020.

[19] Z. Meng, C. Xu, and H. Lan, "Fuzzy GM(1,1) model based per capital income predicted of farmers in the world natural and cultural heritage area: take leshan city for an example," in Proceedings of the International Conference on Management Science \& Engineering Management, pp. 1007-1018, Springer, Guangxi, China, August 2017.

[20] S. Zhang, H. Zhang, and Y. Zhu, "Optimizing social economy prediction based on integration of time series models," in Proceedings of the 2020 35th Youth Academic Annual Conference of Chinese Association of Automation (YAC), pp. 122-126, Zhanjiang, China, 2020.

[21] M. N. Koniagina, "Forecast of budget revenues from taxes in the context of economy digitalization," IOP Conference Series: Materials Science and Engineering, vol. 940, no. 1, 2020.

[22] X. C. Zheng, "Revenue management forecasting: the resiliency of advanced booking methods given dynamic booking windows - ScienceDirect," International Journal of Hospitality Management, vol. 89, no. 2, Article ID 102590. 
[23] J. Fang, "Prediction and analysis of regional economic income multiplication capability based on fractional accumulation and integral model," Chaos, Solitons \& Fractals, vol. 130, Article ID 109441, 2020.

[24] H. Wang, Y. Zhang, and X. Fan, "Gray image segmentation algorithm based on one-dimensional image complexity," Journal of Intelligent and Fuzzy Systems, vol. 38, no. 5, pp. 1-10, 2020.

[25] Y.-C. Hu, "Constructing grey prediction models using grey relational analysis and neural networks for magnesium material demand forecasting," Applied Soft Computing, vol. 93, Article ID 106398, 2020.

[26] Y. C. Hu, "Energy demand forecasting using a novel remnant GM(1,1) model," Soft Computing, vol. 24, no. 18, 2020.

[27] V. Huang and J. Unwin, "Markov chain models of refugee migration data," IMA Journal of Applied Mathematics, vol. 85, no. 6, 2020.

[28] J. Ye, Y. Dang, and B. Li, "Grey-Markov prediction model based on background value optimization and central-point triangular whitenization weight function," Communications in Nonlinear Science and Numerical Simulation, vol. 54, pp. 320-330, 2018. 